
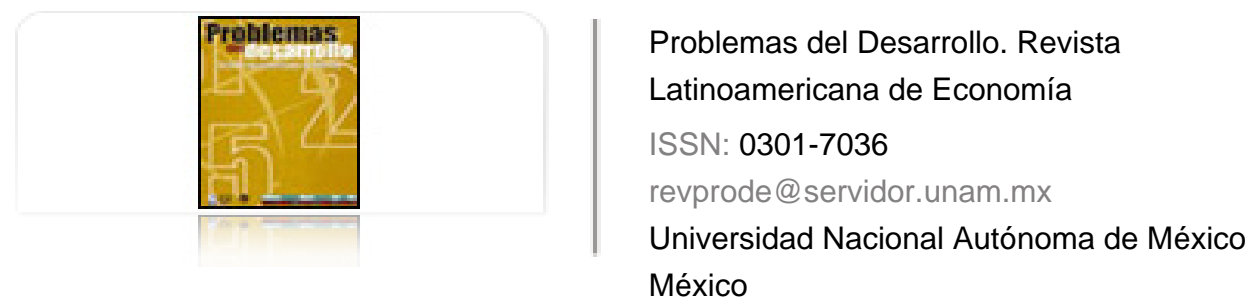

Girón González, Alicia

La moneta: un debate contemporáneo

Problemas del Desarrollo. Revista Latinoamericana de Economía, vol. 36, núm. 142, julio-septiembre, 2005, pp. 127-143

Universidad Nacional Autónoma de México

Distrito Federal, México

Disponible en: http://www.redalyc.org/articulo.oa?id=11820079009

Cómo citar el artículo

- Número completo

- Más información del artículo

Página de la revista en redalyc.org

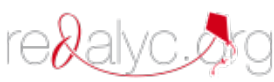

Sistema de Información Científica

Red de Revistas Científicas de América Latina, el Caribe, España y Portugal Proyecto académico sin fines de lucro, desarrollado bajo la iniciativa de acceso abierto 


\title{
LA MONETA: UN DEBATE CONTEMPORÁNEO
}

\author{
Alicia Girón González* \\ Currency is to the science of economy what the squaring of the \\ circle is to geometry, or perpetual motion to mechanics. \\ William Stanley Jevons \\ Money and the Mechanism of Exchange, 1875\}
}

Fecha de recepción: 13 de abril de 2004. Fecha de aceptación: 16 de agosto de 2005.

\section{Resumen}

Este ensayo tiene como objetivo hacer un breve recuento del pensamiento económico en torno a la concepción de la moneda. En el primer apartado, la moneda como medio de intercambio y de acumulación, se intenta hacer un boceto desde Adam Smith y Marx, hasta los pilares de la teoría cuantitativa. En el segundo, acercamiento cartalista, se analiza brevemente la moneda como una creación del Estado. En el tercero se presentan las apreciaciones de los poskeynesianos. Por último, se hace una recapitulación de los máximos exponentes en relación con la apreciación del dinero como medio de intercambio y unidad de cuenta. Estas apuntes han sido primordialmente esenciales en el tipo de politicas aplicadas durante el último siglo de la economía en el nivel internacional. La moneda es un ejercicio del poder en la sociedad.

Palabras clave: moneda, dinero, intercambio, teoría económica monetaria, cartalista.

\section{Abstract}

This essay aims to give a brief account of economic conceptions of money. The first section, money as a means of exchange and accumulation, aims at making a sketch from Adam Smith and Marx to the pillars of quantitative theory. The second, the cartelist approach, briefly analyzes money as a creation of the State. The third gives the appreciations of the postKeynesians. Finally, a review is made of the major exponents with respect to their appreciation of money as a medium of exchange and unit of account. These points have been of fundamental importance in the type of policies applied during the past century of the economy at an international level. Money is an exercise of power in society.

Key words: money, coin, exchange, economic monetary theory, Chartalism.

* Académica y directora del Instituto de Investigaciones Económicas (IIEC) durante 1994 2002. Tutora del Posgrado de Economía de la UNAM. Pertenece al Sistema Nacional de Investigadores nivel II. La autora agradece los comentarios de la maestra Alma Chapoy del IIEC y el apoyo de Roberto Guerra Miligan, responsable del Centro de Información y Documentación Biblioteca "Mtro. Jesús Silva Herzog". Este trabajo es parte del proyecto Reformas y asimetrías financieras: regulación y cooperación financiera regional de la Dirección General de Asuntos Académicos de la UNAM. 
Résumé

Cet essai a pour but de faire un bref rapport de la pensée économique autour de la conception de la monnaie. Dans le premier paragraphe, la monnaie comme moyen d'échange et d'accumulation, on essaie de faire une ébauche depuis Adam Smith et Marx, jusqu'aux piliers de la théorie quantitative. Dans le deuxième, une approche cartaliste, on analyse brièvement la monnaie comme une création de l'Etat. Dans le troisième, on présente les appréciations des post keynésiens. En dernier lieu, on fait un récapitulatif des plus grands exposants en relation avec l'appréciation de l'argent comme moyen d'échange et d'unité de comptes. Ces notes ont été surtout essentielles dans le type de politiques appliquées pendant le dernier siècle de l'économie au niveau international. La monnaie est un exercice du pouvoir dans la société.

Mots clés: monnaie, argent, échange, théorie économique de l'argent, cartaliste.

\section{Resumo}

Este ensaio tem como objetivo fazer um breve reconto do pensamento económico em torno à concepção da moeda. No primeiro apartado, a moeda como médio de intercámbio e de acumulação, tenta se fazer um bosquejo desde Adam Smith e Marx, até os pilares da teoria quantitativa. No segundo, aproximação cartalista, analiza-se brevemente a moeda como uma criação do Estado. No terceiro apresentam-se as apreciações dos poskeynesianos. Por último, se faz uma recapitulação dos máximos expoentes em relação com a apreciação do dinheiro como médio de intercâmbio e unidade de conta. Estas anotações foram primordialmente importantes no tipo de políticas aplicadas durante o último século da economia ao nível internacional. A moeda é um exercício de poder na sociedade.

Palavras chave: moeda, dinheiro, intercámbio, teoria económica da moeda, cartalista. 
$\mathrm{L}$ a moneda y el dinero priorizan el debate contemporáneo e innovador del curso económico. La moneda permite efectuar las relaciones de intercambio en la sociedad, simboliza un vínculo social en las transacciones de esta última. Por otro lado, la autoridad, el Estado, sistematiza las actividades de las personas en un espacio monetario y regula dicha relación social. Por último, la moneda es una creación del Estado. Existen dos paradigmas teóricos en torno a ella. Su origen se establece en la interpretación de sus funciones en las grandes civilizaciones, entre las cuales destacan las siguientes: medida de valor, medio de cambio y dinero crédito, este último es el transformador de las grandes estructuras de los sistemas financieros maduros.

Este ensayo tiene como objetivo hacer un breve recuento de lo que han aportado algunos autores a la concepción de la moneda. Se desarrolla una síntesis de sus diferentes explicaciones en el pensamiento económico contemporáneo. En el primer apartado se intenta hacer un bosquejo desde Adam Smith y Marx hasta los pilares de la teoría cuantitativa del dinero. En el segundo, se analiza brevemente la moneda como una creación del Estado. En el tercero se presentan las apreciaciones de los poskeynesianos. Por último, se hace una reflexión acerca de la moneda, el poder y la sociedad.

\section{La moneda como medio de intercambio y de acumulación}

El origen del dinero y sus funciones han sido tema de debate a lo largo de la historia; desde Aristóteles hasta los economistas contemporáneos han realizado estudios para comprenderlas. Adam Smith, Marx y Keynes tienen una visión contraria a la de los exponentes de la teoría cuantitativa, como Menger, Jevons y Walras. Así pues, existen dos líneas de apreciación del dinero, las cuales se exponen a continuación.

El entorno económico mundial es definitivo en la construcción de la teoría económica prevaleciente, pues determina el debate contemporáneo acerca del dinero.

\section{a) Adam Smith y Marx}

Adam Smith y Marx observaron la moneda-crédito como el único medio que permite el intercambio y con características únicas que la diferencian de las otras mercancías. Menger, al igual que Jevons, vio en los metales (el oro) el medio idóneo para intercambiar aquellas y ambos le dieron una importancia inédita al acto de reciprocidad, es decir, al cambio de mercancías de valores semejantes.

Adam Smith, en su obra An Inquiry into the Nature and Causes of the Wealth of Nations (Investigación sobre la naturaleza y causas de la riqueza de las naciones), ubica el dinero como un acto de confianza al afirmar que:

\section{Desaarrollo}


Existen diferentes clases de papel moneda, pero los billetes en circulación de los bancos y banqueros son los más conocidos y, por otra parte, los que mejor se acomodan a nuestro propósito. Tan pronto como los habitantes de un país llegan a depositar la confianza necesaria en el patrimonio, la probidad y la conducta de un banquero particular, hasta el punto de creer que siempre estará dispuesto a pagar a la vista cualquier pagaré suyo que le sea presentado, no importa en qué momentos, esos efectos circularán lo mismo que si fueran monedas de oro y plata, en virtud de la confianza que inspiran (Smith, 2000:256).

Este acto de confianza entre el banco y la sociedad es la base del dinero crédito o dinero como unidad de cuenta. Es lo que posteriormente utilizará Marx para desarrollar su teoría de la transformación del dinero en cuanto dinero y al dinero en cuanto capital, cuya distinción sólo se da en la forma de circulación. Tomando en cuenta los ciclos:

$$
\text { M-D-M y D-M-D }
$$

las dos formas, primera y segunda, manifiestan el valor de uso permitido de la moneda como la mercancía para intercambiar otras, y como es la expresión del valor de estas mercancías, el trabajo humano implícito en ellas corresponde a la forma dineraria, el equivalente general. La moneda permite la transacción de las diferentes representaciones del valor de las mercancías expresadas en precios.

El segundo paso es la transformación del dinero mediante la producción en una cantidad mayor, donde $\mathrm{D}$ ' es igual a $\mathrm{D}+d$. El proceso de producción capitalista ubica el dinero crédito en el transcurso de la mutación de las mercancías y adquiere una ganancia representada en:

$$
\text { D-M-D }
$$

Dicha fórmula expresa la metamorfosis del capital: dinerario, productivo y mercantil. "En cada uno de los tres ciclos, el impulso motor es el acrecentamiento del valor, o sea D-D'; es ésta la forma determinante del proceso en su conjunto" (Marx, 1976:677).

Tanto en Smith como en Marx existe la concepción del dinero como unidad de cuenta, como el dinero crediticio que permite la transformación de las mercancías para acrecentar la riqueza de la sociedad obteniendo un incremento de capital. Durante los últimos años, la lectura de los clásicos del pensamiento económico y los últimos hallazgos de las primeras civilizaciones han enfatizado el principio del dinero como unidad de cuenta.

\section{b) Menger, Jevons y Walras}

"On the Origin of Money", de Karl Menger (1892:239-255), ubica la moneda medio de intercambio y de valor, reconocida por la sociedad y el Estado para garantizar las opera-

\section{Desarrrollo}


ciones comerciales. En el punto IX hace un recuento del origen del dinero como una relación social sancionada por la ley del Estado para facilitar el comercio:

Todas estas medidas han perfeccionado el funcionamiento de los metales preciosos como dinero, pero con seguridad, no han sido responsables de que éstos se convirtieran en dinero. Sólo se puede entender verdaderamente el origen del dinero si aprendemos a considerarlo como una institución social, como el resultado espontáneo, el producto no planificado de los esfuerzos específicamente individuales de los miembros de la sociedad (Menger, 1892).

A lo largo de su brillante artículo, Menger expresa lo mismo que Marx en el tomo I de El Capital: la expresión del dinero como medio de transacción entre las diferentes mercancías hacia el interior del espacio económico, el equivalente general sancionado por la sociedad para intercambiar el cúmulo de mercancías, olvidando el dinero como unidad de cuenta y creador de la riqueza, en la medida en que participa en el proceso de la producción capitalista. Usa incluso la expresión en latín pecuniam habens, habet omenm requem vult habere ("tener dinero significa tener todo lo que vale la pena tener") (Menger, 1892).

Estas ideas las desarrolla en el capítulo "La teoría del valor" de Principios de economía política, al insistir en la significación que tienen los bienes en relación con las necesidades satisfechas y la escasez de los mismos (Menger, 1997).

Aunado a ello, cobra fuerza el conceptos de escasez, relacionado con el valor de uso en el intercambio, el cual se dará en un mercado de dinero donde éste no significa una situación geográfica. Según Jevons y Jevons: " "se aplica al conjunto de banqueros, capitalistas y otros comerciantes que prestan o toman en préstamo dinero, y que constantemente intercambian información relativa a la marcha del negocio (Jevons, 1998:129)". ${ }^{2}$

La teoría económica monetaria tiene como base la teoría cuantitativa del dinero y su relación con la transacción de mercancías; no debemos olvidar cómo se genera dicha corriente.

El análisis que hace Léon Walras de la teoría del dinero en Elements of Pure Economics in the Theory of Social Wealth ${ }^{3}$ es el más controvertido, pues plantea tres versiones. En la primera, corresponde a la ecuación de transacción, la cual es completamente análoga a la formulada posteriormente por Fisher. En la segunda y tercera edición, el concepto circulation à desservir es sustituido por encaisse désirée, del deseo, muy semejante a la

1 Jevons y Jevons, (1934:225 237). En este artículo plantean el conocimiento de Stanley Jevons en torno a sus investigaciones acerca de la moneda y las innumerables publicaciones que hizo en su corta vida.

2 Jevons (1998) señala que Cournot definió el mercado en Recherches sur les principes mathématiques de la théorie de richesses, París, 1838, p. 55: "On sait que les economistes entendent par marché, non pas un lieu déterminé où se consomment les achats et les ventes, mais tout un territoire dont les parties sont unies par des rapports de libre commerse, en sorte que les prix s'y nivellent avec facilité et promptitude", p. 126.

3 Léon Walras (1834 1910) tuvo una influencia en Wilfredo Pareto, Enrique Barone, Knut Wicksell, Irving Fisher, Henry Ludwell Moore y Joseph Shumpeter. El libro se tradujo por primera vez al inglés en 1926.

\section{Desaarrollo}


formulada posteriormente por Marshall; en la cuarta edición de su texto, Walras presenta una teoría más elaborada, al encontrar la relación entre dinero y circulación de bienes (de consumo y primarios); es decir, el dinero sirve para hacer transacciones, por lo tanto, es útil precisamente por tener la capacidad de intercambiar los productos en el proceso de circulación. Ésta será posteriormente tomada en cuenta por autores como Irving Fisher y Milton Friedman.

La teoría del dinero y la moneda son parte de la discusión de finales del siglo xIX y principios del xx. Este debate define dos corrientes: como unidad de cuenta y de intercambio. Dicho debate se encuentra plasmado en la obra el Tratado del dinero de Keynes (1965) y La teoría cuantitativa de Friedman (1956).

La teoría cuantitativa, basada en los postulados de Marshall y las principales aportaciones de autores como Irving Fisher, fue desarrollada posteriormente, a finales del siglo, por Milton Friedman con base en las concepciones teóricas de autores como Menger, Stanley y Walras. La ecuación se interpreta de la siguiente manera:

$$
\begin{array}{r}
M V=P T \\
\mathrm{MV}+\mathrm{M}^{\prime} \mathrm{V}^{\prime}=\mathrm{PT}
\end{array}
$$

La primera parte de la ecuación expresa el valor total nominal de los pagos durante un periodo dado, en el cual $\mathrm{P}$ = precios y $\mathrm{T}=$ tiempo. En la segunda, $\mathrm{M}$ es el dinero, el stock de dinero, y $\mathrm{V}$, el número de veces que dicho stock sirve para realizar las transacciones en el mercado en una unidad de tiempo.

De esta ecuación surge una larga discusión teórica a lo largo del pensamiento económico, además de que esta corriente influirá en las políticas económicas de las últimas tres décadas en lo que toca a las políticas monetaristas de corte ortodoxo. Si bien fue concebida por los autores mencionados, es determinante en el pensamiento económico contemporáneo, al ser retomada por autores como Irving Fisher, Pigou y Milton Friedman.

Friedman y la escuela de los Chicago boys constituyen una corriente que ha influido de manera relevante en los lineamientos de los planes de política económica de los organismos financieros internacionales y de los bancos centrales en los últimos treinta años, cuyo laboratorio ha sido América Latina.

\section{c) El poder de la moneda en el espacio económico}

El oro como mercancía dineraria amplió la circulación de los productos en el comercio internacional, expresando el poder del capitalismo durante tres siglos. El poder del capital por medio de la moneda, le permitió a Inglaterra el control de un espacio económico mundial. Es importante mencionar que el proceso de desenvolvimiento capitalista, origi-

\section{Desarrrollo}


nado por la innovación tecnológica en la industria, facilitó al imperio británico, desde finales del siglo xvIII y hasta antes de la segunda guerra mundial, dominar el comercio internacional y establecer relaciones de intercambio con el exterior sometiendo a países como Portugal y España. Los metales que este último obtuvo en sus colonias ayudaron a fortalecer el intercambio de mercancías de los ingleses y abrieron la expansión hacia la India y el resto de Asia en el siglo xIx. La transacción de mercancías mediante la moneda de metal oro culminó con la implantación del equivalente general base patrón monetario oro, el cual prevaleció, en sus diferentes modalidades, hasta 1971.

Posterior a esa fecha, la moneda hegemónica, relación social de todas las transacciones de intercambio, fue el dólar. La lucha de las monedas y la propia confrontación entre los diferentes espacios económicos ha sido notable en la última década. El euro y el yen han iniciado una recuperación en espacios geográficos donde algunos consideran que empieza a desdibujarse la presencia del dólar. La lucha por el predominio de una moneda imperial subsiste hasta el día de hoy.

\section{Acercamiento chartalista: dinero, creación del Estado}

El intercambio de las mercancías, expresado en su concepción abstracta, nos lleva al referente de la moneda. Ésta es el embrión del espacio económico que permite la transacción de mercancías. La moneda controla un espacio y lo amplía conforme se va desarrollando el proceso de acumulación y en la integración de más espacios. La moneda de cierta área económica puede prevalecer, aunque difícilmente puede implantarse en otra donde no se hayan generado relaciones previas de producción y circulación del equivalente general dominante. De dichos enunciados se deduce que la moneda expresa no sólo las relaciones de intercambio de una sociedad, sino también entre diferentes tipos de trabajo expresados en cada una de las mercancías, lo cual facilita su circulación y las transacciones comerciales.

Al llevar a cabo el intercambio de mercancías culmina el proceso de valorización, lo cual implica una ganancia que tendrá que ser repartida entre los empresarios: se concluye un ciclo. Nuevamente, el inicio del proceso de producción y circulación, el pago de los salarios y la renovación del capital reactivarán el consumo y procurarán el bienestar. La sociedad tiene el poder de elegir su consumo en función de sus necesidades e ingresos. La participación de la autoridad en el espacio económico, al sancionar la moneda de circulación, crea el crédito —el cual es otorgado por el prestamista—, que se cancela una vez cumplido su objetivo y regresa de manos del prestatario a su origen. Al cancelar la deuda se origina un nuevo asiento para la recreación del crédito.

Marx, Schumpeter y Keynes estudian la moneda y la importancia de la misma en las relaciones de producción y en el desenvolvimiento del capitalismo como la etapa madura del intercambio mediante crédito. El dinero-crédito es una promesa de pago en el tiempo. Representa la confianza entre acreedor y deudor, banquero y empresa, prestamista y pres-

\section{Desaarrollo}


tatario; el proceso del circuito productivo: de la creación y realización del valor hasta la etapa finiquitada por el consumidor.

En las últimas décadas, la nueva lectura del marxismo y los poskeynesianos ha dado una importancia sin igual a la moneda, no sólo en lo que respecta al dinero como unidad de cuenta, sino al papel del crédito en el desarrollo de la economía capitalista en un sistema de producción maduro. Es el Estado, mediante el banco central, el creador del dinero en una sociedad y el que permite a empresas y familias establecer una relación estrecha de intercambio. Con el argumento establecido entre el dinero - como unidad de cuenta- y el trabajo - como creador del valor implícito en la producción-, el dinero pasa por su metamorfosis al realizar el plusvalor en las ventas de las mercancías y crear empleo activador de la demanda agregada. El Estado es el que garantiza el valor de una moneda y el que fija la tasa de interés y la eficiencia marginal de la sociedad. Tales enunciados son totalmente contrarios a la posición ortodoxa del pensamiento hegemónico actual, en la cual la moneda no tiene importancia, el dinero es exógeno a la economía y el banco central tiene como misión controlar la inflación.

\section{a) Innes y Keynes}

Recientemente Randall Wray publicó Credit and State Theories of Money (2004), en el cual destacan dos trabajos de Alfred Mitchell-Innes: "What is Money?" y "The Credit Theory of Money", originalmente editados en Banking Law Journal, en 1913 y 1914, respectivamente. Estos artículos responden al debate en torno al dinero como medio de intercambio y su importancia como unidad de cuenta, cuyo creador es el Estado. Las ideas vertidas en estos artículos y el señalamiento sobre lo dicho por Knapp en su libro The State Theory of Money (1924) las sintetiza Keynes en la siguiente cita de A Treatise on Money (1930): "Todos los Estados modernos se atribuyen este derecho, y así ha ocurrido desde hace al menos cuatro mil años. Esto es lo que Knapp ha llamado el cartalismo, una fase que se alcanza en la evolución del dinero y en la que se cumple plenamente la doctrina de que el dinero es una creación de la ley (Keynes, 1996).

\section{b) Keynes: A Treatise on Money}

Keynes retoma el debate de su época en el Tratado del dinero. El énfasis principal radica en la relación precisa del papel del Estado en la creación del dinero. Es importante mencionar que la palabra utilizada por Keynes cuando define Knapp's Chartalism (o "lo que Knapp ha llamado el cartalismo"), proviene de la palabra chart o carta, es decir, un papel, sancionado por la comunidad, la sociedad y el Estado. Al paso de una economía de intercambio o trueque a una economía monetaria, en la cual el dinero es una unidad de cuenta sancionada por el Estado, se le llama Chartalism o cartalismo. 
Este paso, registrado en los últimos descubrimientos de la historia económica y monetaria en Asia Central, ${ }^{4}$ constituye el avance hacia la madurez en las relaciones de intercambio en una comunidad. Un gran paso de la humanidad es la creación del "equivalente general", el cual responde al proceso de intercambio de productos mediante el trueque y la forma del equivalente general que conforma, en abstracto, una unidad de cuenta concretada en la moneda sancionada por un grupo de personas, la comunidad y la autoridad (Estado). La confianza depositada en el dinero como unidad de cuenta - a diferencia del dinero mercancía, dinero dirigido, dinero fiduciario y dinero bancario, tal como aparece en el siguiente diagrama de Keynes (1996)—, constituye el eje central de su aportación al estudio del dinero contemporáneo. ${ }^{5}$ En dicha gráfica se explica el concepto básico del dinero como unidad de cuenta, es decir, el dinero adelantado por la autoridad del espacio económico para el inicio de la producción y del acto de intercambio entre los integrantes de dicho espacio o sociedad.

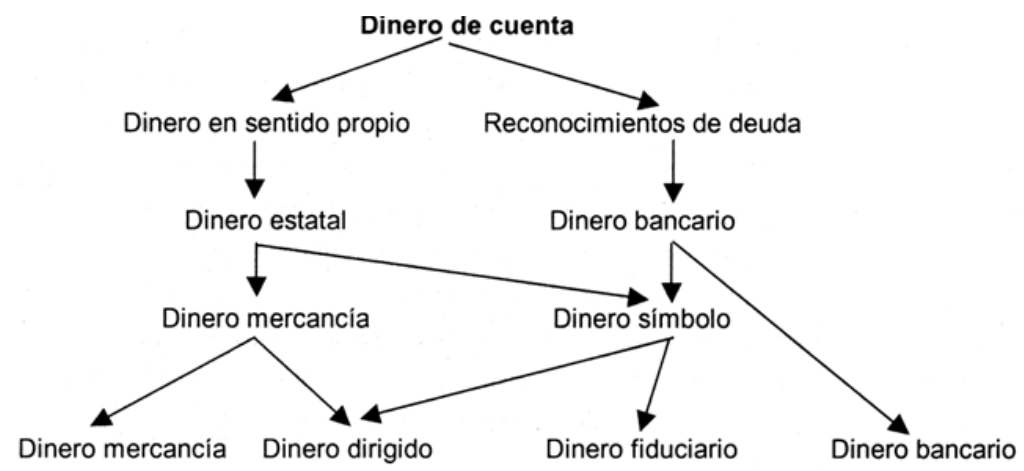

Keynes define el dinero como el medio que permite la cancelación de la deuda:

El dinero (es aquél por medio del cual) sirve para pagar las deudas contraídas, y los precios de los contratos son descontados [...] El dinero bancario puede representar no una deuda privada como en la definición anterior, sino una deuda propia del Estado y el Estado puede entonces utilizar su prerrogativa cartalista para declarar que esa deuda, por sí sola, puede utilizarse para liberar una obligación (Keynes, 1996).

En tanto que el dinero es una creación del Estado, elemento fundamental de la teoría del dinero y de la teoría monetaria de la producción — también dinero bancario-, se

4 En la página electrónica del Museo Metropolitano de New York se encuentra ubicada la exposición de "Las grandes civilizaciones del tercer milenio, a.C.", llevada a cabo durante el año 2003. Allí se muestra el intenso comercio que se efectuaba en esa región entre el vIII y el III milenios a.C., http:/ /www.metmuseum.org/special/First - Cities.

5 Este diagrama se encuentra en el inciso IV, "Las formas de dinero", correspondiente al capítulo I, "La clasificación del dinero", del libro I "La naturaleza del dinero", del Tratado del dinero. 
le define como la suma del dinero en manos de la sociedad, los bancos y el banco central. Keynes lo nombra "dinero corriente" (current money) y corresponde al dinero-renta, dineronegocio y dinero-ahorro analizados en el capítulo 3 del libro I, con el título "La naturaleza del dinero".

La importancia del análisis del dinero y su naturaleza, así como el origen cartalista del mismo, priorizan en la Teoría general la relación entre creación del dinero y empleo. La participación del Estado es pilar de la reactivación de la producción en función de la creación del dinero mediante el banco central. La tasa de interés y la eficiencia marginal del capital serán la garantía del Estado para mantener en equilibrio la preferencia por la liquidez y la inversión.

Según Hicks, la preferencia por la liquidez es la aportación más importante de Keynes a la teoría del dinero. Hicks (1935:1-19) menciona que Keynes maneja tres teorías: a) la teoría del ahorro y la inversión, la cual es cuantitativa —más glorificada-; $b$ ) la teoría wickselliana de la tasa natural; y $c$ ) la más importante, cuando habla acerca del nivelprecio de la inversión en bienes, demuestra que el nivel de precios depende de las preferencias relativas del inversionista, ya sea para poseer depósitos bancarios o para mantener sus valores.

En la teoría de Keynes, la preferencia por la liquidez y el equilibrio de ésta mediante la tasa de interés tiene un significado prioritario en las relaciones económicas y en el empleo. Él señala que:

la preferencia por la liquidez es una potencialidad o tendencia funcional que fija la cantidad de dinero que el público guardará cuando se conozca la tasa de interés; de tal manera que si $r$ es la tasa de interés, $M$ la cantidad de dinero y $L$ la función de preferencia por la liquidez, tendremos $M=L(r)$. Tal es la forma y lugar en que la cantidad de dinero penetra en el mecanismo económico (Keynes, 1965).

La teoría de la preferencia por la liquidez está relacionada con el futuro y la incertidumbre en la teoría monetaria de la producción y con las necesidades de transacción diarias en la economía, la precaución para el futuro y la especulación.

$$
M=L(r)
$$

De allí que la preferencia por la liquidez y la inversión dependan de la eficiencia marginal del capital y de la tasa de interés.

c) La moneda de Estado

A lo largo de sus dos libros, Keynes define la importancia de la moneda como una creación del Estado. Una de las principales diferencias entre la concepción ortodoxa y heterodoxa 
del dinero es la forma en que la moneda se integra a la macroeconomía. Rochon y Verdengo (2003) enfatizan: "la moneda es en primer lugar el resultado de una relación de endeudamiento entre las empresas productivas y los bancos; ella es introducida en el sistema económico para la producción y el pago de los salarios".

La moneda la crea el Estado por medio del banco central por ser una economía monetaria de la producción. El dinero creado por el banco central y otorgado a los empresarios en préstamos de corto (salarios) y mediano plazo (bienes de capital) fluye nuevamente al banco. Pero es éste, a su vez, el que introduce la tasa de interés para fijar las necesidades del dinero para la economía. El Estado se financia mediante impuestos y logra ejercer la preferencia o no preferencia por la liquidez de las empresas. Al ejercer el gasto, el Estado reactiva la economía monetaria y con ello previene el riesgo del ciclo económico. A su vez, el Estado contrarresta la incertidumbre en el futuro, al mantener un equilibrio entre la tasa de interés y la eficiencia marginal del capital.

La eficiencia marginal del capital se define "en términos de expectativa del rendimiento probable y del precio de oferta corriente del bien de capital". Es decir, cuando Keynes está hablando en el libro IV del incentivo para invertir, hay dos palabras que definen el curso de la economía y son riesgo y futuro, las cuales centran la preferencia por la liquidez y el grado de inversión del empresario en el equilibrio que existe entre tasa de interés y eficiencia marginal de capital. Justo en este equilibrio, "la tasa neutral de interés puede definirse más estrictamente como la que prevalece en equilibrio cuando la producción y la ocupación son tales que la elasticidad de la ocupación como un todo es cero" (Keynes, 1965). La importancia de la moneda como creación del Estado y la relación de éste con el banco central en su definición de la tasa de interés y la eficiencia marginal del capital garantizan una economía monetaria de la producción en equilibrio. Las expectativas a futuro no sólo minimizan el riesgo, sino que relacionan linealmente la función del dinero con el empleo.

Al introducir la moneda al circuito productivo como una creación del Estado, las funciones del dinero cobran una importancia determinante en el ciclo económico y el crecimiento de la economía. La moneda de Estado, creada por el banco central, cobra una importancia en el análisis teórico keynesiano y poskeynesiano, a diferencia de la visión ortodoxa de Friedman y los monetaristas. Rompe con la ilusión del dinero como medio de cambio y con los principios clásicos y neoclásicos de la economía.

\section{Teorías poskeynesianas:} nuevas aportaciones al estudio de la moneda

En las últimas dos décadas las aportaciones al estudio de la moneda, del dinero como unidad de cuenta y las apreciaciones teóricas en cuanto al funcionamiento del banco central,

\section{Desaarrollo}


política monetaria y política fiscal, han sido muy pertinentes para explicar el actual modelo económico. A la corriente del pensamiento económico basada en los estudios de Innes, Kahn y especialmente Keynes se le llama poskeynesianismo, cuyas aportaciones merecen un tratado. En este apartado se introduce el concepto básico de la moneda y se delinean algunas concepciones en torno a las apreciaciones de dicha corriente.

\section{a) ¿Qué es la moneda?}

John Smith en What is Money? (2000) menciona que las relaciones en una economía capitalista o en una economía de mercado siempre se refieren al dinero: hacer dinero, ganarlo, gastarlo, ahorrarlo y otras más. Los cambios recientes en la tecnología han llevado, incluso, al concepto de "dinero virtual" (cashless society or virtual money). La economía capitalista establece como principio el análisis monetario, por tanto, el empleo y la producción dependen de las expectativas monetarias relativas a los costos monetarios y, en general, toda la estructura depende de asientos contables (entradas y salidas). En otras palabras, el dinero es el costo de adquirir recursos financieros como parte integral del proceso económico.

En Understanding Modern Money: The Key to Full Employment and Price Stability, Randall Wray señala que, efectivamente, el análisis convencional de la moneda se dirige a su uso como medio de cambio, por lo cual su valor estaría determinado por el que representa el metal precioso. Ello, no obstante que desde la definición de la moneda como unidad de cuenta, manifiesta el valor de las mercancías que se pueden comprar con la forma dineraria representada en la moneda. Por lo tanto, la tasa de inflación estaría presumiblemente controlada por el banco central. Desde este punto de vista, en primera instancia, la política monetaria controla la oferta monetaria, mientras que la política fiscal lo tendría que hacer mediante el gasto del gobierno, los impuestos y sus préstamos (Wray, 1998:18).

Para Wray, la visión ortodoxa convencional de la moneda no tiene nada que ver con la visión chartalist que se traza desde Adam Smith hasta John Maynard Keynes, en la cual la moneda es una creación del Estado y, por lo tanto, es la forma en la cual la sociedad regresa una parte al Estado mediante los impuestos para su uso. La moneda en el capitalismo es una creación de la autoridad que permite el intercambio en la sociedad y, al mismo tiempo, es un instrumento de poder frente a ésta. Es decir, ejerce un poder sobre la circulación de las mercancías y sobre la valoración de las mismas en el circuito productivo al extraer un tributo para el gasto de la autoridad soberana en una nación. También es la forma en la cual se guarda el equilibrio entre los bancos, las empresas y las familias mediante el ejercicio equitativo de la compra y la venta de las mercancías, de la adquisición de crédito y el pago de las deudas, así como de la reparación en la participación del intercambio por medio de la tasa de interés, la ganancia y el pago de salarios.

\section{Desarrrollo}




\section{b) Acercamiento y comprensión de la aceptación social del dinero}

Los postulados más importantes del pensamiento dominante en torno a la moneda radican en los pilares de la escasez y en su función como medio de cambio. Por lo tanto, la moneda es neutral en el largo plazo y plantea una relación estrecha entre la tasa de inflación y el desempleo en el corto plazo.

La mayoría de los modelos macroeconómicos enfatizan el intercambio de las mercancías, en las cuales el precio es el punto de equilibrio. ${ }^{6}$ Los agentes económicos son las empresas y las familias, cuyas decisiones se sitúan en mercados perfectamente competitivos. El dinero es importante porque su creación en el corto y largo plazos puede ser inflacionaria, no porque aumente la oferta monetaria sino porque sin su creación, la producción no puede llevarse a cabo.

La crítica a la concepción neoclásica del dinero está en las aportaciones de Keynes en el Tratado de dinero y en la Teoría general. La publicación de estas dos obras en la década de los treinta reabrió el debate en torno a la importancia del estudio de la moneda y el dinero. Si bien las preocupaciones más importantes de la época en la cual Keynes desarroló la Teoría monetaria de la producción son el empleo y la reactivación de la economía, el dinero es la columna vertebral de la economía y su creación corresponde a ampliar la demanda agregada a la creación de mayores empleos. La producción en la economía no puede ser estudiada sin el dinero, por ello, la Teoría monetaria de la producción permite desarrollar posteriormente la endogeneidad de la moneda. La creación monetaria es un fenómeno contemporáneo en virtud de la existencia de los bancos y de la creación del crédito sobre la demanda de la economía y del empleo. La economía capitalista es una economía monetaria y, por tanto, la visión de la moneda como unidad de intercambio no facilita la interpretación del desarrollo económico. La aceptación de la moneda por la sociedad y por el Estado como unidad de cuenta es, según Lerner (1947:313), la clave para que el Estado cobre impuestos.

\section{c) Las corrientes del pensamiento poskeynesiano}

En 1978 se publicó A Guide to Post Keynesian Economics (Holt y Pressman, 2001), en la cual Alfred Eichener introdujo el debate entre keynesianos y monetaristas. Si bien ese libro sirvió para establecer las bases de las primeras ideas de los poskeynesianos, los cambios ocurridos durante las dos últimas décadas en el nivel mundial cambiaron el panorama teórico-económico de la interpretación del capitalismo y de sus políticas. Las últimas décadas confrontan no sólo el paradigma poskeynesiano, sino que se han esclarecido

6 Walras lo señala en "Lesson 11, Problem of Exchange of Several Commodities for one Another. The Theorem of General Equilibrium", en Elements of Pure Economics in the Theory of Social Wealth (1977:152).

\section{Desaarrollo}


algunas brechas mediante la lectura de Straffa, Kalecki, Kaldor y Robinson. El proyecto de John Kenneth Galbraith, Sydney Wintraub y Paul Davidson se cristaliza en la revista Journal of Post Keynesian Economics, en 1978, la cual se convierte en el semillero crítico de los últimos años para las interpretaciones y aportaciones de nuevas generaciones formadas en el pensamiento poskeynesiano. En la introducción de Modern Theories of Money: The Nature and Role of Money in Capitalist Economies, de Rochon y Rossi, se plantean las cuatro corrientes poskeynesianas existentes en relación con la formulación del papel del dinero en la economía: primera, los American Post Keynesians, en la cual el dinero, ligado a la perversa incertidumbre es central; destaca por su análisis Paul Davidson, editor del Journal of Poskeynesians.

Segunda, los poskeynesianos seguidores de Minsky enfatizan las fluctuaciones del ciclo económico y del empleo como resultado de la innovación financiera, relacionada con la incertidumbre. Explican la endogeneidad del dinero y la debilidad del banco central para controlar la oferta monetaria y evitar las crisis financieras (Minsky, Pollin, Palley). Estas dos líneas del pensamiento se ubican, según los autores, en la corriente estructuralista.

Tercera, los poskeynesianos de Cambridge, cuyos exponentes más destacados son Joan Robinson, Kahn y Kaldor. La prioridad en torno a la endogeneidad del dinero en la producción es el eje central de sus aportaciones a la teoría económica. Los recientes trabajos de Moore, Lavoie y Rochon enfatizan la endogeneidad del dinero. El lineamiento principal es ubicar la curva de la oferta monetaria con tendencia horizontal.

Cuarta, los circuitistas centran el estudio del dinero en su origen histórico, el nivel de la actividad económica, el desempleo y su relación con las políticas de estabilización. Se destaca la incorporación de conceptos marxistas y schumpeterianos al estudio de la problemática financiera. Parguez en Francia, Graziani en Italia y la escuela Dijon-Fribourg explican la naturaleza de los asientos contables activo-pasivo, como la naturaleza moderna del dinero, por su doble entrada a los bancos.

\section{d) Alan Parguez y la teoría monetaria del capitalismo}

Una de las aportaciones más importantes a la teoría monetaria del capitalismo son los trabajos de Alan Parguez, quien explica de manera muy clara la no neutralidad del dinero en la economía y la tasa de interés exógena y su determinación por el banco central. El artículo "Money and Credit in Contemporary Capitalism or The Monetary Theory of Capitalismo" (Correa y Girón, 2004) define en cuatro puntos centrales esta teoría: 1) el dinero es creado en la fase del flujo del circuito monetario para realizar el gasto requerido del Estado y de las empresas; 2) el dinero es destruido en la fase del reflujo, cuando el circuito monetario de las empresas y el Estado recuperan el monto al inicio del circuito; 3 ) el dinero acumulado como reserva no existe, pues es inconsistente con la ley del valor en una economía capitalista y tiene sólo valor cuando se gasta; 4) la moneda es una

\section{Desarrrollo}


abstracción simbólica creada por el Estado como unidad de cuenta. Convencionalmente, son deudas creadas por el Estado mediante el banco central y cuya contraparte es el crédito que los bancos otorgan a las empresas. Creada y destruida en la producción y adquisición de nuevas mercancías.

Lo interesante de las aportaciones de Alan Parguez es su visión al entrelazar la creación del dinero estatal y las empresas, en la cual el sistema corporativo tiene una obligada relación con la creación del bienestar en un espacio monetario.

\section{Reflexiones}

El debate innovador de la moneta y el dinero en torno a una economía monetaria y productiva se establece al partir del origen del dinero como una unidad de intercambio y el dinero como una unidad de cuenta. Dos paradigmas del pensamiento económico que han dominado la política económica en diferentes periodos durante el siglo xx. Las aportaciones del pensamiento poskeynesiano, la teoría del circuito productivo y la teoría regulacionista, alternativas al pensamiento predominante, han permeado los círculos académicos en los cuales el dinero, como una institución social, toma otras dimensiones en el análisis de la realidad de la economía monetaria y productiva en los últimos años.

La discusión predominantemente ortodoxa que permanece en los círculos académicos internacionales ha penetrado hondamente el carácter de las políticas monetarias, fiscales, sobre tasas de interés y tipo de cambio que promueven los organismos financieros internacionales con ayuda de los estados, y han llevado a largos periodos alternativos de crecimiento, recesión y deflación de la economía. El impacto de las políticas señaladas con anterioridad no ha resuelto los problemas del empleo y el aumento de la capacidad de consumo. La situación en Europa, Estados Unidos, Japón y, por supuesto, Latinoamérica, es prueba de ello.

En este debate acerca del origen del dinero y su importancia en una economía monetaria de producción, cabe destacar la endogeneidad de la política monetaria y su relación estrecha con el Estado. Igualmente, éste necesita de la política fiscal para limitar o expandir la demanda agregada y fincar el desarrollo económico. El financiamiento al desarrollo en economías latinoamericanas, en las cuales la brecha entre importaciones y exportaciones hace posible el crecimiento económico, impide el desarrollo. La necesidad de mantener una tasa de desempleo alta y una expulsión de la mano de obra de los procesos productivos hacia el interior de las naciones redunda en ganancias extraordinarias para las grandes corporaciones y en una disminución del consumo de la población y, por lo tanto, de los ingresos del Estado.

Al menos, es importante mencionar algunos de los estudios alternativos más importantes de las dos últimas décadas en torno al dinero y su relación con el Estado y la

\section{Desaarrollo}


mundialización financiera. Estos trabajos son de M. Aglietta y A. Orlean (2002), Françoise Chesnais (2003), P. Piégay y Louis-Philippe Rochon (2003).

La moneda y el hombre o el hombre y la moneda son la identidad de una relación de intercambio y cuyo intercambio sólo se da entre los hombres, dicha relación se considera un salto en la civilización. Sin embargo, recientes descubrimientos arqueológicos señalan no sólo a la moneda símbolo del equivalente, sino la talea como unidad de cuenta, dinero crédito, en las transacciones de intercambio, que se facilitó en forma madura en las civilizaciones del tercer milenio a.C. en Asia central. Estas últimas revelaciones aportan material inédito al estudio del dinero como unidad de cuenta, ejercido desde la antigüedad en la anticipación del acto de confianza de otorgar un equivalente en el uso anticipado del ejercicio del intercambio y la producción.

El hombre y la sociedad maduran cuando han pasado del intercambio de las mercancías al intercambio por medio de la talea como una unidad de cuenta. Innes afirma: "el crédito y la deuda no tienen y nunca han tenido nada que ver con el oro y la plata" (Innes, 2004:54). La relación entre vender y comprar representa el intercambio de una mercancía por un crédito, lo cual es una relación social. Estas transacciones estrechan la convivencia de los seres en un espacio económico dado, al establecer un equivalente (equivalente general). Al mismo tiempo, se desarrolla la unidad de cuenta, el crédito, el cual no sólo agiliza las transacciones comerciales entre mercancías, sino también los circuitos de la esfera productiva y financiera. La moneda, más que una concepción abstracta, pertenece al hombre y a la sociedad en una relación dialéctica, una vez que hay un proceso de maduración del desarrollo de las civilizaciones. La moneda es poder en manos de la autoridad. El poder en los medios de intercambio de la sociedad es sancionado por la autoridad. Es ahí en la cual ésta controla el espacio económico por medio de la moneda. El ejercicio del poder monetario determina el espacio económico y, a su vez, el fortalecimiento del intercambio. Las sociedades maduras que ejercen el poder monetario promueven el bienestar económico del pueblo mediante el crédito otorgado por el Estado.

Es necesario agregar que el estudio del dinero, como unidad de cuenta, en las transformaciones económicas y financieras de América Latina durante los últimos sesenta años es muy importante. El juego de la moneda y el dinero, desde una perspectiva del debate contemporáneo en torno al financiamiento del desarrollo, favorecen, primordialmente una alternativa diferente a la acción del financiamiento. Si bien en esta síntesis del debate contemporáneo de la moneda no se incluye cómo lograr un financiamiento proveniente de estructuras financieras maduras - en el espacio económico de las relaciones de intercambio en América Latina-, es un tema que posteriormente se podría analizar con un enfoque innovador que posibilite un financiamiento del desarrollo en la región. 


\section{Bibliografía}

Aglietta, Michel, El fin de las divisas clave (ensayo sobre la moneda internacional), México, Siglo XXI, 1987.

$-\mathrm{y}$ A. Orlean, La monnaie entre violance et confiance, México, Siglo XXI, 2002.

Branam, Sophie y Michel Cazals, La Monnaie, París, Dunod, serie Éco, 1997.

Chesnais, Françoise, La mondialisation financière, París, Syros, 2003.

Correa, Eugenia y Alicia Girón, Economía financiera contemporánea (4 tomos), México, Miguel Ángel Porrúa, 2004.

Davidson, Paul, "Money and the Real World", en The Economic Journal, vol. 82, núm. 325, marzo de 1972, pp. 101-115.

Dillard, Dudley, La teoría económica de John Maynard Keynes (Teoría de una economía monetaria), Madrid, Aguilar, 1968.

Friedman, Milton, "The Quantity Theory of Money: a Restatement", en John Eatwell, Murria Milgate y Meter Newman, The New Palgrave: dictionary of economics, Londres, Macmillan, 1989.

Guttman, R., Cybercash: The Coming Era of Electronic Mone, Basingstoke, Palgrave Macmillan, 2003.

Hicks, J.R., "A Suggestion for Simplifying the Theory of Money", en Economica, New Seires, vol 2, num. 5, febrero de 1935, pp. 1-19.

Holt, Richard P.F. y Steven Pressman, A New Guide to Post Keynesian Economics, Nueva York, Routledge, 2001.

Jevons, H. Winefred y H. Stanley Jevons, "William Stanley Jevons", Econometrica, vol 2, núm. 3, julio de 1934, pp. 225-237

Jevons, William Stanley, La teoría de la economía política, Madrid, Pirámide, 1998.

Keynes, John Maynard, A Treatise On Money, Volume I The Pure Theory of Money, Londres, Macmillan, 1965.

_, Teoría general de la ocupación, el interés y el dinero, México, Fondo de Cultura Económica, 1965.

- Tratado del dinero, Madrid, Acosta, 1996.

Knapp, George Friedrich,The State Theory of Money, Nueva York, Augustus M. Kelley, 1973.

Lerner, Abba P., "Money as a Creature of the State", en The American Economic Review, vol. 37, núm. 2, mayo de 1947, pp. 312-317.

Marx, Karl, "El proceso de circulación del capital (Friedrich Engels)", en El Capital, t. II, México, Siglo XXI, 1976, pp. 641-684.
,"El proceso de producción del capital", en $E l$ Capital, t. I, México, Siglo xxi, 1975, pp. 43-214.

Menger, Karl, "On the origin of money", en Economic Journal, vol. 2, núm. 6, Londres, 1892, pp. 239-255.

, Principios de economía política, Madrid, Unión Editorial, 1997.

Mitchell Innes, Alfred, "The Credit Theory of Money", en The Banking Law Journal, vol. 31, diciembre/enero de 1914, pp. 151-168.

, "What is Money?", en The Banking Law Journal, mayo de 1913, pp. 151-168 y 377-408.

Montesano, Aldo, "A revision of Walras: Theories of Capitalization and Money", en Festschrift in honour of Lazaros Th. Houmanidis, Atenas, Piraeus, 1991.

Parguez, Alan, "Moneda y Crédito en el capitalismo contemporáneo", en Eugenia Correa y Alicia Girón, Economía financiera contemporánea, t. II, México, Miguel Ángel Porrúa, pp. 15-54.

Piégay, Pierre y Louis-Philippe Rochon, Théories monétaires post keynésiennes, París, Economica, 2003.

Rochon, Louis-Philippe y Matías Vernengo, "La monnaie d'État et le monde réel: le malaise du chartalisme" en Pierre Piégay y Louis-Philippe Rochon, Théories monétaires post keynésiennes, París, Economica, 2003. y Sergio Rossi, Modern Theories of Money, Londres, Edward Elgar, 2003.

Schumpeter, Joseph A., Teoría del desenvolvimiento económico (Una investigación sobre ganancias, capital, crédito, interés y ciclo económico), México, Fondo de Cultura Económica, 1967.

Smith, Adam, Investigación sobre la naturaleza y causas de la riqueza de las naciones, México, Fondo de Cultura Económica, 2000.

Smith, John, What is Money?, Nueva York, Routledge, 2000.

Walras, Léon, Elements of Pure Economics in the Theory of Social Wealth, Nueva York, Augustus M. Kelly, Fairfield, 1977.

Wood, Geofrey, Money, Prices and the Real Economy, Londres, Institute of Economic Affairs y Edward Elgar, 1998.

Wray, L. Randall (2004) Credit and State Theories of Money (2004), Londres, Inglaterra, Edward Elgar, $271 \mathrm{p}$.

Wray, L. Randall, Understanding Modern Money (The Key to Full Employment and Price Stability), Londres, Edward Elgar, 1998.

\section{Desarrrollo}

